RUNNING HEAD: Audience Tailoring

Tailoring Narration for Distinct Audiences in Emerging Adulthood

M. Pasupathi ${ }^{1}$, K. C. McLean ${ }^{2}$, T. L. Weeks ${ }^{1}$, \& W. Hynes ${ }^{3}$

${ }^{1}$ Department of Psychology, University of Utah

${ }^{2}$ Department of Psychology, Western Washington University

${ }^{3}$ Department of Psychology, Idaho State University

Corresponding Author:

Monisha Pasupathi, PhD

Professor of Psychology

Associate Dean for Academic and Faculty Affairs, Honors College

University of Utah

1975 DeTrobriand Street

Building 619, Fort Douglas

Phone: 801-587-1155

Fax: 801-585-5034

KEYWORDS: Narrative Identity, emerging adulthood, parent-child relationships, peer relationships, audience effects 


\begin{abstract}
The development of narrative identity is a critical task for emerging adults - one shaped by parents and peers. However, how diverse audiences might jointly shape narrative identity remains underexamined. The present study addresses this gap, examining how emerging adults perceive diverse audiences for their narratives, and tailor those narratives. In Study 1 emerging adults $(n=112$ and 106) rated peer audiences as more frequent, comfortable, agreeable, and less challenging audiences compared to mothers and fathers. In Study 2 participants $(n=106 ; n=$ 1272 narratives) responded to four narrative prompts: first, the standard prompt with no audience specified, and then edited those narratives (if desired) for mothers and for friends. Broadly, relative to friends, mothers elicited more positive, but also more edited, narratives. These findings illustrate the social-relational dynamics of narrative identity construction in emerging adulthood, as well as implications for narrative autonomy and narrative intimacy.
\end{abstract}

Key Words: Narrative Identity, emerging adulthood, parent-child relationships, peer relationships, audience effects 


\section{Tailoring Narration for Distinct Audiences in Emerging Adulthood}

The transition to adulthood is a key period for narrative identity development (e.g., Erikson, 1968; McAdams \& McLean, 2013), as narrative identity builds from child and adolescent beginnings (e.g., Habermas \& Bluck, 2000; Köber, Schmiedek, \& Habermas, 2015; Reese, Jack, \& White, 2010), to a more integrated a sense of self through time, across context, and between self and society (Syed \& McLean, 2016). Narrative identity is conceptualized as a life story - a selective autobiographical account that provides an account of who a person is, how they came to be that person, and offers some projection into possible futures (McAdams \& McLean, 2013). Approaches to the study of narrative identity often focus on the way people narrate key episodes from the overall life story -e.g., turning points, low points, and high points (Adler, Dunlop, Fivush, Lilgendahl, Lodi-Smith, McAdams, McLean, Pasupathi, \& Syed, 2017). This life story develops from a lifelong history of narrating events, through which people develop narrative capacities and proclivities as well as begin to assemble the key episodes that they treat as central to their emerging life story (McAdams \& McLean, 2013; Pasupathi, Mansour, \& Brubaker, 2007). Emerging adults who develop a life story that is elaborated, growth-focused, and resolved report higher well-being (Adler, Lodi-Smith, Philippe, \& Houle, 2016).

Building an elaborated, positive life story is a developmental achievement that is deeply embedded in the social contexts of people's lives. It requires the deployment of autobiographical reasoning, through which people connect experiences to their sense of themselves (Habermas \& Bluck, 2001). Such reasoning is scaffolded through the activity of narrating one's experiences with others from early childhood through emerging adulthood, although the bulk of extant research examines parents and few studies have focused on peers (e.g., Fivush \& Nelson, 2006; 
McLean \& Mansfield, 2012; McLean \& Jennings, 2012; Pasupathi \& Hoyt, 2009; Weeks \& Pasupathi, 2011). The lack of attention to peers as potential scaffolders of narrative identity is a major gap in the literature because of the increasingly important role that peers play in socialemotional development as youth move through adolescence and into emerging adulthood (e.g., Hartup \& Stevens, 1997). Further, during emerging adulthood, the representation of listeners is likely to have implications for narration even when people do so in solitary contexts. We examine how emerging adults represent parent and peer audiences for narrative identity construction, and how the same event is narrated distinctly with different intended audiences to understand the role that parents and peers may play as distinct scaffolders of narrative identity.

\section{Relational Variations in the Primary Audiences for Emergent Adults}

Emerging adults narrate to friends, romantic partners, and parents (e.g., McLean, 2005; Thorne, McLean, \& Lawrence, 2004), but these different relational contexts involve different kinds of bonds (Ainsworth, 1991). Parent-child relationships involve caregiver and attachment bonds, which are intrinsically asymmetric in nature - parents provide care and nurturing, and children seek and receive such care well into emerging adulthood (Andersen, Lavoie, \& Dunkel, 2007; Fraley \& Davis, 1997). In contrast, peer relationships are more egalitarian, and involve bonds of the "affiliative" system (Ainsworth, 1991). Romantic partnerships also draw on the affiliative system as well as attachment, caregiving, and reproductive systems (Ainsworth, 1991; Fraley \& Davis, 1997), but do so in more symmetric ways than do parent-child relations (Fraley \& Davis, 1997). In sum, parent-child relationships are likely to retain their asymmetry into emerging adulthood, while peer relationships entail more mutuality.

Peer and parent-child relationships also differ in the extent of overlap in the selves of the two parties. Children's experiences are relevant to their parents' own well-being, likely because 
parents' sense of self encompasses their children's actions and achievements (Kalmijn \& De Graaf, 2012; Ryff, Lee, Essex, \& Schmutte, 1994). By contrast, while friends often identify and empathize with one another about the distressing and joyous events in one another's lives, disclosing important experiences to peers may have less intense impact on peers' own affective experience given clearer self-other boundaries in these relationships. In short, parents may have more of a stake in the kinds of stories their children tell and the way they tell them, than do peers, which may have consequences for how young adults perceive these audiences as listeners.

\section{Different Relationships, Different Narrative Purposes, and Different Responses}

People narrate events for varied purposes, such as creating and sustaining a sense of self and forging and maintaining connections to others (e.g., Liao, Bluck, Alea, \& Cheng, 2016). For self-related purposes, existing work establishes that both parents (especially mothers, McLean \& Mansfield, 2012; Weeks \& Pasupathi, 2010) and peers (both friends and romantic partners, Jennings, McLean, \& Pasupathi, 2013; Pasupathi \& Hoyt, 2009) play a role in narrative identity development. Though not investigated to our knowledge, the self-overlap and asymmetry in parent-child relationships suggests that sharing stories with parents will be less likely to involve social purposes like intimacy building or advice/support giving, compared to peers.

Relational differences also suggest differences in how listeners are experienced by emerging adult storytellers. Listener responses vary in terms of attentiveness/responsiveness versus distraction, and agreement versus challenge, whether assessed via narrator's perceptions or listener's behavior (Jennings et al., 2013; Nils \& Rimé, 2012; Pasupathi, Carstensen, Levenson, \& Gottman, 1999; Pasupathi \& Hoyt, 2009). Because both parents and peers are invested in their relationships with emerging adults, we expect both to be attentive and responsive listeners. But the asymmetric nature of parent-child relationships may be related to 
more challenging or disagreeable responses compared to peer relationships (McLean \& Jennings, 2012; Recchia \& Wainryb, 2014; Weeks \& Pasupathi, 2010). Indeed, parent-child relationships may be able to withstand conflict more than peer relationships, which are discretionary and more fragile (Shaver, Furman, \& Buhrmeister, 1985). Further, the investment that parents have in their children and their stories may manifest as more controlling listener behavior in comparison to peer audiences.

\section{Differences in Purposes and Responses are Likely to Relate to Differences in Stories}

Studies of in-vivo and retrospective narration show that the goal of the narrator (which varies with audience) shapes the story told (see Pasupathi, 2001 for a review). For example, differences in purposes for narrating and in listener responses, are related to whether narratives are elaborated, involve exploration of identity themes, and construct a sense of growth and resolution (McLean, 2005; Pasupathi, 2007; Pasupathi \& Hoyt, 2009; Weeks \& Pasupathi, 2011), such that when people narrate for self-related purposes, their narratives are more elaborative and meaning-laden (McLean, 2005; Pasupathi, 2007).

Listener behavior also shapes narratives. Narrators reduce the elaboration and exploration of their narratives when talking with less responsive listeners (Bavelas, Coates, \& Johnson, 2000; Pasupathi \& Hoyt, 2009; Reese, Haden, \& Fivush, 1993), and emphasize meaning and elaborate less detail with disagreeable listeners (Pasupathi \& Hoyt, 2009; Weeks \& Pasupathi, 2010). Few studies have compared audiences, but one small study showed that mothers were more likely to explicitly promote meaning-making in narration relative to peers, although peers provided room for exploration of events that may be harder to share with mothers (McLean \& Jennings, 2012).

\section{Current Studies}


The primary goals of the present studies were to examine 1) how emerging adults represent different audiences for narrative identity construction, and 2) the relation of those representations to how emerging adults construct particular narratives. We present data from two samples of college-going emerging adults. We surveyed both samples about the frequency, experiences, and purposes of narrating to parents, friends, and in one sample, romantic partners. In addition, the second sample provided narratives about important experiences intended for mothers or friends as audiences, allowing comparisons of the actual narratives created for distinct listeners. For clarity, the data are presented as two studies, with Study 1 addressing the survey data from both samples and testing hypotheses about the purposes for and experience of narrating to different audiences. In Study 2, we examine the actual narratives shaped for divergent audiences in terms of traditional narrative identity constructs (e.g., elaboration), but also introduce a novel method to examine how the events are edited for mothers and friends. We provide full sample descriptions for both samples in Study 1, but measures and procedures are described in the context of the questions they addressed. Specific hypotheses are introduced in the context of each of the studies.

\section{Study One Introduction}

We surveyed two samples of emerging adults about their perceptions of parents and peers as audiences for narration. We asked about how frequently participants narrate experiences to specific audiences to document the emergence of friends as a central audience in this age range (McLean, 2005; Pasupathi \& Hoyt, 2009). We assessed a variety of specific purposes designed to tap the two broad functions of self and social orientations (for related approaches see Bluck \& Alea, 2011; Pasupathi, McLean, \& Weeks, 2009). We hypothesized that peers and parent audiences would only differ for social functions, with peers more preferred for those purposes. 
We assessed overall comfort with telling parents and peers; based on our assumption that parents are more challenging listeners, we expected peers to be more 'comfortable' audiences. In one sample, we assessed listener responses along responsiveness and challenge dimensions (McLean \& Jennings, 2012; Pasupathi et al., 2009; Weeks \& Pasupathi, 2011). We anticipated that peers and parents might be similarly responsive, but that parents would be more challenging.

\section{Study 1 Methods}

\section{Participants}

Sample 1. One-hundred and fourteen college students were recruited from two public universities in Eastern Canada $(n=65)$ and the Western United States $(n=49)$; two participants had sufficient missing data to be excluded, leaving an overall sample size of 112 (campus was unrelated to any results). They averaged 20 years old $(S D=3.6)$, were majority female $(\mathrm{n}=82)$ and White $(n=63)$, followed by Asian $(n=32)$, Latin-x $(n=6)$, and other identities $(n=11)$. Some parents also completed surveys about memory telling with their child, but these data were not included in the present study.

Sample 2. One-hundred and six participants were recruited from a collegiate participant pool at the US college in Sample 1. The sample averaged 20 years of age $(S D=3.2)$, majority female $(n=70)$, and majority White $(n=83)$, followed by Asian $n=(17)$, Mixed $(n=9)$, Latin-x $(n=6)$ and other $(n=4)$; note that participants could select more than one ethnic label.

Power. Our primary analyses were within-participant general linear models examining the effects of audience on the experience of narrating. Gpower 3.1 (Erdfelder, Faul, \& Buchner, 1996) suggested that given the repeated measures design, sample sizes around 50-54 (depending on the assumptions used $)$ give adequate power $($ Beta $=.95)$ to detect medium effects.

\section{Survey Procedure}


Following informed consent, participants completed surveys about the types of topics, purposes, and experiences they had with narrating important life events to various audiences. Sample 1 provided ratings for mothers, fathers, and friends; Sample 2 also rated romantic partners. In both samples, the surveys were completed following other narrative procedures; those narrative procedures used in Sample 2 are the basis of Study 2, and are described in the methods for that study. Please see https://tinyurl.com/y592xd22 for full list of materials for both studies.

\section{Survey Measures.}

Telling Frequency. Participants rated how frequently they narrated to each audience on 7point Likert type items; higher ratings indicate greater frequency.

Purposes for Narrating. Participants responded to 11 Likert-type items rated on 7-point scales (higher numbers represent greater endorsement of a given purpose). Specific items were: 1) getting advice or help; 2) sharing oneself; 3) entertainment; 4) feeling closer to the listener; 5) validating opinions/feelings; 6) understanding the memory better; 7) explaining oneself; 8) show understanding of listener; 9) make listener feel better; 10) help the listener; and 11) teach the listener something. The items were designed to capture directive, social, and self-related purposes (Bluck \& Alea, 2011; Pasupathi \& Wainryb, 2018). Exploratory factor analyses to reduce variables produced only two factors: self-regulatory (including self and directive purposes); and social purposes. We aggregated items related to self (items $1,3,4,5,6,7$ ) and other $(2,8,9,10$, and 11). See https://tinyurl.com/y592xd22 for factor analytic results.

Experience with Listener. For both samples, participants rated how comfortable they were sharing memories with each type of listener on a single, 7-point Likert type scale; higher ratings represented greater comfort. In addition, for Sample 1, we also asked participants to rate 
how each audience typically responded to narration along 9 Likert-type items that tapped attentiveness, responsiveness, and disagreeable behavior (see, e.g., Pasupathi \& Hoyt, 2009). Exploratory factor analyses of these items within each audience type consistently yielded a factor related to supportive and engaged listening (attentive, supportive, agreeable, open, not distracted; e.g., "Mom seemed distracted"), and one related to hostile and challenging listening (angry, challenging, controlling; e.g., "Mom challenged my perspective". See the https://tinyurl.com/y592xd22 for details.

\section{Study One Results}

\section{Analytic Strategy}

For both samples, we examine audience differences in telling: frequency, purposes, and experiences. We report GLM analyses with the multivariate main effect of audience, univariate effects of audience on specific measures, and where appropriate, pairwise comparisons with Bonferroni correction using an alpha criterion of .05 for determining significance. We report effect sizes as partial $\eta 2$, and estimated marginal means and the standard error of the mean, $\operatorname{EMM}(S E M)$. Table 1 provides descriptives for major variables.

\section{Frequency of Narrating}

Sample 1. A GLM revealed a significant effect of audience, $F(2,104)=35.5, p<.001$, partial $\eta 2=.41$. Fathers elicited the lowest frequency of narration, $\operatorname{EMM}(S E M)=3.7(.16)$, followed by mothers, $E M M(S E M)=4.5(.14)$, and friends, $E M M(S E M)=5.4(.13)$; all of these differences were significant.

Sample 2. The GLM revealed a significant main effect of audience, $F(3,101)=43.4, p<$ $.001, \eta 2=.56$. Fathers were rated as the least frequent audience, $\operatorname{EMM}(\operatorname{SEM})=3.2(.17)$, followed by mothers, $E M M(S E M)=4.6(.19)$, friends, $E M M(S E M)=5.2(.13)$ and romantic 
partners, $\operatorname{EMM}(S E M)=5.4(.15)$. Pairwise comparisons showed that fathers were significantly different from all other audiences and that friends and romantic partners did not differ. Differences between mothers and romantic partners were significant, and differences between mothers and friends were not $(\mathrm{p}=.06)$.

\section{Purposes of Narrating}

Sample 1. A GLM of purposes by focus (self vs. social) and audience revealed significant effects of audience, $F(2,104)=34.07, p<.001$, partial $\eta 2=.53$, and an interaction of focus and audience, $F(2,104)=19.8, p<.001$, partial $\eta 2=.28$. Regardless of purpose, fathers were least preferred, $E M M(S E M)=3.9(.13)$, mothers were in between, $\operatorname{EMM}(S E M)=$ 4.4(.12), and friends most preferred, $\operatorname{EMM}(S E M)=5.3(.10)$; all pairwise comparisons were significant. The interaction effect arose because differences by audience were larger, on average for social purposes $(|\mathrm{Mdiff}|=1.11)$ than for self purposes $(|\mathrm{Mdiff}|=.69)$.

Sample 2. The GLM revealed overall multivariate effects of audience, $F(3,100)=43.9$, $p<.001$, partial $\eta 2=.57$, and the predicted interaction of focus (self vs. social) and audience, $F(3,100)=14.7, p<.001$, partial $\eta 2=.31$. Consistent with Study 1 , fathers were rated as significantly less likely recipients for memory sharing for both purposes, $\operatorname{EMM}(S E M)=3.6(.15)$, with mothers in the middle, $\operatorname{EMM}(S E M)=4.5(.16)$, and friends and romantic partners rated similarly and highly, $\operatorname{EMM}(S E M)$ friends $=5.2(.10), \operatorname{EMM}(S E M)$ romantic $=5.3(.13)$.

Differences by audience were larger, on average, for social purposes $(\mid$ Mdiff $\mid=1.18)$ than for self purposes $(|\mathrm{Mdiff}|=.75)$.

\section{Experience of Telling}

Comfort, Sample 1. A GLM of comfort by audience revealed only a significant main effect for audience, $F(2,103)=34.1, p<.001, \eta 2=.40$. Fathers were the least comfortable 
audience, $\operatorname{EMM}(S E M)=4.2(.15)$, then mothers, $\operatorname{EMM}(S E M)=5.0(.15)$, then friends, $E M M(S E M)=5.8(.13)$; all pairwise comparisons were significant.

Comfort, Sample 2. A GLM of comfort by audience and gender revealed a main effect of audience, $F(3,101)=29.0, p<.001, \eta 2=.46$. Pairwise comparisons showed that fathers, $\operatorname{EMM}(S E M)=3.9(.19)$ were rated as significantly less comfortable than mothers, $E M M(S E M)=$ 4.9(.19), friends, $E M M(S E M)=5.7(.13)$ and romantic partners, $E M M(S E M)=5.8(.14)$. Mothers were less comfortable audiences than friends and romantic partners, and the latter two did not differ.

\section{Perceived Listener Behavior, Sample 1 only. A GLM of supportive and} challenging/hostile listening yielded a significant main effect of audience, $F(4,103)=6.9, p=$ .001 , partial $\eta 2=.21$. Audience effects were attributable to both supportive, $F(2,212)=9.2, p=$ .001 , partial $\eta 2=.08$, and hostile listening, $F(2,212)=7.1, p=.002, \eta 2=.06$. Fathers were reported as least supportive, $E M M(S E M)=4.9(.10)$, with mothers, $E M M(S E M)=5.2(.10)$ and friends, $E M M(S E M)=5.3(.08)$ viewed as similarly and relatively highly supportive. Friends were viewed as the least hostile, $E M M(S E M)=2.5(.10)$, with fathers, $E M M(S E M)=2.9(.12)$, and mothers, $E M M(S E M)=2.9(.12)$ viewed as similarly and somewhat more hostile, although ratings of hostility were low.

\section{Study One Discussion}

Across two different samples, fathers were consistently reported as less frequent and comfortable audiences, and participants reported a lower likelihood of narrating to fathers for both purposes. Mothers were rated as moderately frequent and comfortable audiences, but as less likely audiences for social purposes than friends and romantic partners. Friends and romantic partners were reported as highly frequent and comfortable audiences. For Sample 1, reports of 
listener behavior also fit this overall pattern - with fathers perceived as providing less supportive listening than mothers and friends, and friends perceived as providing less challenging/hostile listening than mothers and fathers. Thus, by emerging adulthood, peers are a more frequent and positively experienced audience, and used for more social purposes, than are parents, especially fathers. From a developmental standpoint, this suggests that by emerging adulthood, peers may be positioned to have relatively greater influence on the developing life story in adulthood than parents.

\section{Study Two Introduction}

These differences in Study 1 may also have more complex implications for how narrative identity may develop from emerging adulthood onwards. When emerging adults have such distinctive representations of parents and peers as listeners, those differences may be related to variability in how they construct narratives with these different audiences "in mind." Indeed, the narratives people construct in solitary contexts are likely shaped by previous listeners (Pasupathi \& Hoyt, 2010; Pasupathi \& Oldroyd, 2015), and tuned towards the anticipated knowledge and interests of their intended listeners (Echterhoff, Higgins, \& Groll, 2005). We focused on tuning towards the anticipated listener for mothers and friends, given that Study 1 shows fathers to be a relatively less preferred audience and that not all participants will have current romantic partners (we were also limited in the number of narratives we could reasonably ask participants to generate).

We first asked participants to provide typed narratives about significant events in their life stories using the typical narrative prompts, which do not specify the audience (Adler et al., 2017). We then asked participants to edit the resulting narratives for sharing them with their mother and their friend. We used track changes to record participants' changes, and as a result, 
we could examine audience effects on narratives in two ways. First, we could examine whether the intended audience (original, mother, friend) was related to the quality of the narratives produced in terms of traditional narrative measures: elaboration, exploration, growth, damage, and resolution (Adler et al., 2016; Pals, 2006). Second, we could examine the number and nature of edits participants used to adapt their stories for mothers and friends.

Because friends were viewed as more supportive and comfortable audience than were mothers, we might expect narratives for friends to be more elaborated, exploratory, and less edited. But existing studies of in-vivo co-narration with mothers versus friends suggests that mothers may be more likely to press for elaboration and exploration (McLean \& Jennings, 2012; Recchia, Wainryb, Bourne, \& Pasupathi, 2014). Thus, we test competing predictions about narrative quality drawn from these sets of findings. In terms of edits, given growing autonomy and secrecy from parents across adolescence and into emerging adulthood (e.g., Keijsers, Brnaje, Frijns, Finkenauer, \& Meeus, 2010), we expected narratives to be more edited for mothers than friends.

Importantly, to permit a broad test of audience effects on narratives, we included multiple important life story events - high, low, and turning point narratives (McAdams, 1993). These feature the worst and best moments of one's life, and events in which one experiences a change or transition in self-understanding. We also examined narratives about transgressions, which pose a threat to a sense of the self as a good person, and make the construction of meaning around that event important for identity (Lilgendahl, McLean, \& Mansfield, 2013; Mansfield, McLean, \& Lilgendahl, 2010; Mansfield, Pasupathi, \& McLean, 2015).

\section{Study 2 Methods}

\section{Participants.}


This study involved Sample $2(n=106)$ from Study 1. Participants provided 12 narratives each for a total of 1,272 observations.

\section{Design}

We contrasted audience (standard prompt, mother, friend) and event (low point, transgression, turning point, and high point) in a fully within-subjects design. The standard prompt always came first, and the order of mother and friend was counterbalanced. Order of audience did not matter and is not discussed further. Order of events was not counterbalanced in order to ensure that participants finished each segment and the study on a positive note. At https://tinyurl.com/y592xd22, we report participant ratings of the four events.

\section{Procedure}

Participants first provided narratives about the four events using the standard prompts developed by McAdams and colleagues (McAdams, 1996). They were then given their initial narratives and asked to edit them. They were told that they could edit as little (none) to as much (full event replacement) as they wanted (https://tinyurl.com/y592xd22 provides full prompts).

\section{Measures}

For narrative coding we followed accepted guidelines (Syed \& Nelson, 2015), and employed two strategies. First, coders coded the "final" versions of the four narratives for each audience for narrative qualities. Second, coders evaluated the nature of the edits. Manuals are available at https://tinyurl.com/y592xd22.

Narrative Quality. Narratives were coded for 1) elaboration (amount of detail), 2) the exploration of self implications, 3) growth, 4) damage, and 5) the degree to which the narrative was resolved. The coding scheme was adapted from previously published work from our own and others' research programs (Lilgendahl, 2006; Mansfield, Pasupathi, \& McLean, 2015; 
Wainryb, Pasupathi, Bourne, \& Oldroyd, 2018). Coding was completed by two teams of undergraduate coders, trained and supervised by the third author, with two coders evaluating each narrative. Coders did not code the same narrative across audiences. Ratings from both teams were averaged to produce scores for analysis, and agreement (intraclass correlations) was very good (ICCs ranged from .79 to .95).

Editing. Edits were identified by turning on the 'view track changes' option. The fourth author and a research assistant (blind to study aims) classified the type and function of edits. Major types of edits were: insertions, in which the participant added new information into the original text without removing something else; deletions, in which the participant removed information from the original text without adding anything in its place; replacements, in which the participant removed something from the original text and substituted different information; minor, in which the participant made a correction such as spelling, grammar, capitalization, or punctuation; and other, in which the edit did not fit any of the other categories.

Functions were classified as making the narrative more factual (providing additional verifiable facts); making the narrative more interpretive (more reflective of the narrator's subjective view), and other. This last category was further classified as audience directed, (e.g., "My mother disliked that." was changed to, "I know how you hate that."); event replacement, in which the participant wrote a narrative about a different event (e.g., a narrative about a sexual encounter is replaced with a narrative about a sports achievement); entire event deletions without replacement; minor changes, (e.g., "I was mad" becomes, "I was angry"); and fourth wall, in which the participant addressed the researcher directly in the narrative (e.g., "You need to understand that my mother doesn't take anything lightly"). 
Codes were aggregated across the four stories separately for mother-directed and frienddirected edits to obtain the overall number of changes made from the original narratives, as well as the proportion of those edits that added, subtracted, or replaced material; the proportion of those edits which served to increase the interpretive/meaning-focused nature of the story; and the proportion that served to adapt to the knowledge of a particular person, or were references to the "fourth wall". Finally, we counted the number of whole event replacements for each type of audience. The fourth author trained a research assistant on $10 \%$ of the data; after which that author and the research assistant independently coded the remaining data. Twenty percent of the remaining data was jointly coded by the two during coding to prevent coder drift. Thirty percent of the remaining narratives were coded independently by both coders, and this $30 \%$ provided evidence for excellent reliability (edits, kappa $=.96)$ and sub-types of edits $($ kappa $=.90)$.

\section{Study 2 Results}

\section{Narrative Quality Comparisons by Event Type and Audience}

A GLM of the five narrative quality features (elaboration, exploration, growth, damage, and resolution) as a function of event type (high point, low point, transgression, turning point) and audience condition (standard prompt, mother, friend) revealed significant main effects of event type, $F(15,82)=55.7, p<.001$, partial $\eta 2=.91$, audience, $F(10,87)=13.8, p<.001$, partial $\eta 2=.61$, and a significant interaction of event type and audience, $F(30,67)=5.5, p<$ .001, partial $\eta 2=.71$.

Event type effects were evident for elaboration, $F(3,288)=13.6, p<.001$, partial $\eta 2=$ .12 , exploration, $F(3,288)=22.6, p<.001$, partial $\eta 2=.19$, growth, $F(3,288)=44.7, p<.001$, partial $\eta 2=.32$, damage, $F(3,288)=88.4, p<.001$, partial $\eta 2=.48$, and resolution, $F(3,288)=$ 5.9, $p<.002$, partial $\eta 2=.06$. As shown in Table 2 , low point narratives were more elaborated 
than the other narratives, which did not differ from one another. For exploration, low points and turning points were highest (and did not differ from one another), followed by transgressions and high points, which did not differ from one another. For growth, turning points were significantly higher than all events, followed by high points, which were significantly higher than low points, and transgressions, which did not differ. For damage, low points and transgressions were similarly highest, with turning points significantly lower than low points and transgressions and higher than high points. Finally, for resolution, turning points and high points differed significantly from one another, with turning points significantly more resolved than high points. Broadly, these differences are consistent with prior work showing that negative experiences elicit more elaborated, exploratory, damage-containing, and growth-themed contents (McLean \& Lilgendahl, 2008), but show that event differences extend beyond emotional valence, in that transgressions were sometimes similar to low points, but at other times, distinct (see also Lilgendahl \& McLean, 2019)

Audience effects were evident for elaboration, $F(2,192)=9.9, p<.001, \eta 2=.09$, exploration, $F(2,192)=8.7, p<.001$, partial $\eta 2=.08$, growth, $F(2,192)=32.6, p<.001, \eta 2=$ .25 , and damage, $F(2,192)=20.9, p<.001, \eta 2=.18$, but not for resolution, $F(2,192)=2.4, p=$ .091 , partial $\eta 2=.03$ (see Table 2 for means and standard deviations by audience). Narratives written for standard prompts and friends were similarly elaborated, and both were more elaborative than those written for mothers. Narratives written for standard prompts and friends elicited similar levels of exploration, but significantly less exploration than those for mothers. Mother-oriented narratives elicited the most growth, followed by standard prompts, and then friends. Mother-oriented narratives elicited the least damage, followed by friends, and then standard prompts; pairwise comparisons showed that for damage and growth, all audience 
conditions differed significantly from one another. In sum, mothers elicited less elaborate, damage-themed narratives but more explored and growth-promoting narratives than friends; standard prompts were similar to friends or in between.

The interaction of event type and audience was evident for exploration, $F(6,576)=3.3$, $p$ $<.005, \eta 2=.03$, growth, $F(6,576)=4.6, p<.001, \eta 2=.05$, damage, $F(6,576)=15.5, p<$ $.001, \eta 2=.14$, and resolution, $F(6,576)=6.9, p<.001, \eta 2=.07$. To follow-up, we examined the effects of audience within each event type for narrative qualities. For exploration, audience differences were not evident in transgression narratives. For growth, the pattern of audience effects was distinct for each event (see Table 2). Friends generally elicited the lowest growth across all four events. What shifted was whether narratives written for friends or mothers were similar to the narratives elicited by the standard prompt. For damage, narratives written for mothers generally contained lower damage than narratives produced for standard or friend prompts, but this was mainly for low points and transgressions. For resolution, friend narratives were significantly less resolved in low points than mother narratives or the standard narratives, which did not differ. For turning points, the standard narratives were less resolved than were narratives for friends or mothers, which did not differ. Thus, across different types of events, imagined mothers, relative to friends, elicit more exploratory and growth-oriented and less damage-themed narratives. However, beyond audience, both the prompt and the narrative feature matter, and we discuss the meaning of these interactions in the discussion.

\section{Edits by Event Type and Audience}

We asked participants to edit their standard prompt narratives for friends and mothers, so the tracked edits analyses focus only on that comparison. 
Overall number of edits. A GLM of number of edits as a function of event type and audience revealed significant main effects of event type, $F(3,103)=10.9, p<.001$, partial $\eta 2=$ .22 , audience, $F(1,105)=10.0, p=.002$, partial $\eta 2=.08$, and their interaction, $F(3,103)=2.9$, $p<.05$, partial $\eta 2=.07$. Estimated marginal means showed that low points elicited the most edits, $\operatorname{EMM}(S E M)=3.4(.5)$, followed by transgressions, $E M M(S E M)=2.4$ (.3), turning points, $\operatorname{EMM}(\operatorname{SEM})=1.7(.3)$, and high points, $\operatorname{EMM}(S E M)=1.5(.3)$. Pairwise comparisons showed that low points differed significantly from all other event types, and that transgressions differed from low points and high points. Across all event types, mothers elicited more edits, EMM(SEM) $=2.6(.3)$, than friends, $\operatorname{EMM}(S E M)=1.9(.3)$. Finally, we examined the effect of audience within each type of event. Mothers and friends differed only for low points $(p=.04)$, and transgressions $(p=.02)$, but not for turning points $(p=.07)$, or high points $(p=.60)$. Thus, the most negative events tend to be the most tailored, and mothers elicit more edits especially for those negative events.

Type of Edit: Event and Audience. A GLM of the proportions of insertions, deletions, and replacements as a function of event type and audience revealed only two multivariate main effects: event type, $F(9,97)=5.7, p<.001$, partial $\eta 2=.34$; and audience, $F(3,103)=5.7, p=$ .001 , partial $\eta 2=.14$. For event type, effects were driven primarily by deletions, $F(3,315)=9.9$, $p<.001$, partial $\eta 2=.09$, and replacements, $F(3,315)=5.1, p=.002$, partial $\eta 2=.05$.

Pairwise comparisons showed that for deletions, high points $E M M(S E M)=.07(.02)$ elicited significantly fewer deletions than low points, $E M M(S E M)=.21(.03)$, transgressions, $E M M(S E M)=.19(.03)$, and turning points, $E M M(S E M)=.18(.03) ;$ and the latter three types of events did not differ from one another. For replacements, high points, $E M M(S E M)=.14(.02)$, differed significantly from low points, $E M M(S E M)=.22(.03)$, and transgressions, $E M M(S E M)=$ 
.22 (.03), but not from turning points, $E M M(S E M)=.17(.03)$; no other pairwise comparisons reached conventional statistical significance. As above, more negative events elicited more deletions and replacements.

For audience, univariate tests suggested that the audience effect was primarily evident in replacements, $F(1,105)=11.3, p=.001$, partial $\eta 2=.10$, and in deletions, $F(1,105)=4.1, p=$ $.045, \eta 2=.04$. Mothers elicited more replacements, $E M M(S E M)=.23(.03)$, than did friends, $E M M(S E M)=.15(.02)$; the same pattern was evident for deletions, $E M M(S E M)$ mothers= $.18(.02), E M M(S E M)$ friends $=.14(.02)$. So, the pattern of more edits for mothers is driven by replacements and deletions, rather than the insertion of additional information.

Impact of Edits on Narrative Content: Event and Audience. A GLM of the proportion of interpretive edits versus factual edits as a function of audience and event type revealed a significant main effect of event type, $F(6,100)=3.1, p=.007$, partial $\eta 2=.16$, and a main effect of audience, $F(2,104)=3.5, p=.035$, partial $\eta 2=.06$. Univariate tests showed that the effect of event type was primarily due to the proportion of edits that were factual, $F(3,315)=$ 5.9, $p=.001$, partial $\eta 2=.05$. Pairwise comparisons showed that low points, $\operatorname{EMM}(S E M)=$ $.24(.03)$, transgressions, $E M M(S E M)=.20(.03)$, and turning points, $E M M(S E M)=.18(.03)$ had similar levels of edits focused on increasing factual elaboration, while high points elicited fewer factual edits, $E M M(S E M)=.12(.02)$. Transgressions and low points differed significantly from high points; turning points were not significantly different from any other type of event. Audience effects were primarily due to the proportion of edits that made narratives more interpretive, $F(1,105)=7.0, p=.009$, partial $\eta 2=.06$, with mothers eliciting fewer of these edits, $E M M(S E M)=.15(.02)$ than friends, $E M M(S E M)=.21(.03)$. In sum, edits are directed at 
factually elaborating negative events more than positive events, and at making narratives more interpretive for friend audiences than mother audiences.

"Other" function edits. Edits that did not increase the factual or interpretive elaboration of the narrative were classified as adaptations to audience knowledge, changes intended for the researcher audiences ("fourth wall"), whole event replacements, and minor changes. Because the latter two types of edits were rare, we focused on GLM analyses of adaptations to audience knowledge as a function of event type and audience. This analysis revealed main effects of event type, $F(3,103)=5.1, p=.002$, partial $\eta 2=.13$, and audience, $F(1,105)=10.0, p=.002$, partial $\eta 2=.09$. For event type, low points elicited the most such edits, $E M M(S E M)=.16(.03)$, followed by transgressions, $\operatorname{EMM}(S E M)=.13(.03)$, turning points, $E M M(S E M)=.09(.02)$, and high points, $E M M(S E M)=.09(.02)$; differences between low points and turning points, and between low points and high points were statistically significant. More audience-knowledge adjustments were made for mothers, $E M M(S E M)=.16(.03)$ than for friends, $\operatorname{EMM}(S E M)=$ $.08(.02)$

Descriptively, whole event replacement was more likely for transgressions, and was more likely for mothers $(n=20)$ than for friends $(n=9)$ across all types of events. Summing across the four events within each audience, fourth-wall edits averaged $.19(S D=.68)$ for mothers and .11 $(S D=.56)$ for friends - large standard deviations reflect the very low prevalence of these edits.

\section{Study Two Discussion}

This study focused on how emerging adults narrated different types of experiences to perceived mother and friend audiences, and included a comparison to the standard, audienceunspecified narratives. Mothers as imagined audiences elicited more exploration and growth, and less damage than the imagined friend audiences, as well as more edits. Mothers were less likely 
to elicit edits that made narratives more interpretive, and more likely to elicit edits that adapted to listener knowledge. Participants seldom replaced an entire narrative with a different event. Even for deeply identity-challenging events like transgressions and low points, participants typically told the same story in a slightly different way to mothers and to friends. This openness and capacity to flexibly adapt narratives about the same important event to different audiences may be an important aspect of narrative identity development that warrants further study. While the ability to shift narratives based on the knowledge of one's audience is evident quite early (Reese \& Brown, 2000), the type of tailoring we saw in this study was linked to identity-related contents - growth, damage, or exploration. Further, the tailoring we observed in this study presents challenges - emerging adults must negotiate the fact that different stories, elicited by different audiences, may challenge the integrative function of narrative identity.

We also saw hints that the impact of audiences on narrative qualities and edits depended on the nature of the event. A detailed consideration of these interactions is premature without replication. However, one general commonality was that more negative events were more differentially edited, and bore more of the positive skew for mothers than did more positive events.

\section{General Discussion}

Emerging adults rated peer listeners, relative to parent listeners (and especially compared to fathers), as more frequent, comfortable, agreeable, and supportive listeners for their narratives; moreover, they reported more frequently telling friends and romantic partners about their experiences for self-focused and socially focused purposes. They also constructed more heavily edited and somewhat positively oriented narratives when they had mothers in mind, versus friends. The perceived global differences in mothers and friends as listeners suggest that when 
emerging adults construct narratives with mothers in mind, their more exploratory and positive (more growth, less damage) narratives may be in part to satisfy the demands of a listener perceived as more challenging. By contrast, when they construct narratives with friends in mind, they are building a narrative that engages in more consideration of negativity - differences that are aligned with a listener perceived as more supportive, agreeable, and open to the narrator's perspective. Next, we consider the implications for the development of narrative identity.

\section{Secure Bases and Safe Havens in Forging Narrative Identity: Narrative Autonomy and}

\section{Narrative Intimacy}

In early childhood and adolescence, mothers can play an important role in helping youth construct narratives that are elaborated, explore emotion and identity, resolve the experience, and that draw positive conclusions about themselves (Cleveland \& Reese, 2005; Fivush, Marin, McWilliams, \& Bohanek, 2009; Habermas, Negele, \& Mayer, 2010; McLean \& Mansfield, 2012; Reese, Yan, Jack, \& Hayne, 2010). Those types of narratives promote adaptive identity and self-development (Lilgendahl \& McAdams, 2011; McLean, 2016; McLean \& Pratt, 2006; Reese, Yan, et al., 2010). Mothers' long-standing role as a scaffolding force is still evident during emerging adulthood via perceptions of mothers as a frequent, comfortable, and relevant audience for narration, if less so than peers, and in the finding that narratives generated for mothers are more exploratory. By emerging adulthood, however, peers take a prominent and preferred role as audiences for participants' narration. Peers may play an especially important role in creating a safe audience with which to consider negative and damaging aspects of experience (McLean \& Jennings, 2012).

Insofar as our participants narrated the same events to friends in ways that were less growth-promoting, more likely to explore damaging meanings, and less resolved (for low 
points), our findings raise new questions about the links between how people narrate experiences in specific contexts, and the range of meanings they may make of those experiences in other narrative circumstances. That is, our participants had available negative interpretations and a less resolved version of the same event. Because emerging adults' identity is also of consequence for their mothers in ways that are not the case for friends (e.g., Ryff et al., 1994), the narratives elicited for mothers may reflect a 'best case scenario'. Such 'ideal narratives,' as with ideal selves, might provide inspiration for self-development (Cross \& Markus, 1991), and have qualities related to higher well-being (Adler et al., 2016), but might also reflect inhibitory processes that carry risks for developing a coherent and integrated narrative identity. Exploring the implications of these discrepancies is an important direction for future work.

Implications for broader developmental tasks. A developmental shift in emerging adults' relationships away from a primary focus on parents, to a more adult focus on peers is likely adaptive in forging emerging adults' narrative identity to permit flexibility across relationships and contexts. Such changes might also reflect the development of narrative autonomy - particularly in moves to exclude parents from at least some aspects of narrative identity. Those exclusions may be motivated by protective feelings towards mothers, but also by the desire to carve out privacy and separation from mothers. Both are signals of maturation seeing the mother as a person with her own concerns and stresses (e.g., Andersen et al., 2007; McLean, 2015), and forging a self that is not entirely accessible to mother (e.g., Kerr \& Stattin, 2000). This idea raises the possibility of narrative as a means for establishing autonomy and intimacy across adolescence and emergent adulthood.

Indeed, adolescents seek to establish individuation - to show themselves to be independent, capable, and mature individuals - but also to maintain intimacy with parents (Allen, 
Hauser, \& Bell, 1994). In narrative terms, our participants conceive of peers and parents as listeners in ways that foster intimacy with peers, and affirm some separation from parents. Minimizing damage for mothers suggests a stronger, more mature narrative identity and protects mothers, while disclosing damage to friends conveys vulnerability and promotes intimacy. So, one audience is not 'better' than the other. Rather, having mothers who push for a "healthier" narrative, and friends who allow for a more raw narrative is helpful in that it provides options for young adults to narrate events in varied ways while building an overall narrative identity, perhaps also encourage narrative flexibility, a developmentally mature way of allowing stories to shift depending on personal and contextual needs.

Fathers. Fathers appear to play a more limited role in narrative identity development given that they are a less preferred and frequent audience for personal narration. However, the imagined audience of the father may be particularly interesting to investigate to understand more about why they are less preferred beyond the perception ratings, as well as whether there are moderators of this relation, such as relationship quality.

\section{Limitations, Strengths, and Conclusions}

Narrative identity development may unfold differently in non-collegiate samples who tend to enter into adult roles and relationships earlier (Arnett, 2004). We also do not know if these effects would be similar or different in different ethnic or cultural communities that have different values regarding the involvement and role of parents in their children's lives. Finally, we do not know if the perceptions of peers and parents that we examined are congruent with invivo behaviors. It is important to investigate diverse groups of emerging adults and in-vivo narration, because such conversation remains important for shaping memory and self in this age range (Jennings et al., 2013; McLean \& Pasupathi, 2011; Pasupathi \& Hoyt, 2009; Pasupathi \& 
Oldroyd, 2015; Weeks \& Pasupathi, 2011). Given the significant narrative demands of Study 2 for participants, we focused on a limited number of potential audiences - but it will be important to understand how additional audiences play roles in narrative identity development.

The strengths of our study include replication of our survey findings across samples, and the novel paradigm for examining how representations of important audiences might shape people's narratives, using a large number of narratives. Taken together, our results add to the understanding of emerging adulthood stage by demonstrating the ways in which narration and audiences are shifting, and suggesting how narration as a practice may be part of the means by which individuals emerge into adulthood. Indeed, over the long term, elaboration, exploration, and meaning-making in identity-relevant narratives are related to well-being (Adler et al., 2016), self-conceptions (Pasupathi et al., 2015), the extent to which events are included in one's life story (Pasupathi et al., 2015; Pasupathi, Mansour, \& Brubaker, 2007), and have lasting effects on memories for experiences (Pasupathi \& Hoyt, 2010; Pasupathi \& Oldroyd, 2015). When parents and friends "in mind" elicit different stories, they may enable greater complexity in emerging adults' narrative identities. 


\section{References}

Adler, J. M., Dunlop, W. L., Fivush, R., Lilgendahl, J. P., Lodi-Smith, J., McAdams, D. P., . . . Syed, M. (2017). Research methods for studying narrative identity: A primer. Social Psychological and Personality Science, 8(5), 519-527. doi:10.1177/1948550617698202

Adler, J. M., Lodi-Smith, J., Philippe, F. L., \& Houle, I. (2016). The incremental validity of narrative identity in predicting well-being: A review of the field and recommendations for the future. Personality and Social Psychology Review, 20(2), 142-175. doi:10.1177/1088868315585068

Ainsworth, M. D. S. (1991). Attachments and other affectional bonds across the life cycle. In C. M. Parkes, J. Stevenson-Hinde, \& P. Marris (Eds.), Attachment across the life cycle. (pp. 33-51). New York, NY: Tavistock/Routledge.

Allen, J. P., Hauser, S. T., \& Bell, K. L. (1994). Longitudinal assessment of autonomy and relatedness in adolescent-family interactions as predictors of adolescent ego-development and self-esteem. Child Development, 65, 179-194.

Andersen, B., LaVoie, J. C., \& Dunkel, C. S. (2007). Individuation and parents as people: Measurement concerns regarding two aspects of autonomy. Journal of Adolescence, 30(5), 751-760. doi:10.1016/j.adolescence.2006.10.004

Arnett, J. A., (2004). Emerging adulthood: The winding road from the late teens through the twenties. New York: Oxford University Press.

Bavelas, J. B., Coates, L., \& Johnson, T. (2000). Listeners as co-narrators. Journal of Personality and Social Psychology, 79, 941-952. 
Bluck, S., \& Alea, N. (2011). Crafting the TALE: Construction of a measure to assess the functions of autobiographical remembering. Memory, 19(5), 470-486. doi:10.1080/09658211.2011.590500

Cleveland, E., \& Reese, E. (2005). Maternal structure and autonomy support in conversations about the past: Contributions to children's autobiographical memory. Developmental Psychology, 41, 376-388.

Cross, S., \& Markus, H. (1991). Possible selves across the life span. Human Development, 34, 230-255.

Echterhoff, G., Higgins, E. T., \& Groll, S. (2005). Audience-tuning effects on memory: The role of shared reality. Journal of Personality and Social Psychology, 89, 257-276.

Erdfelder, E., Faul, F., \& Buchner, A. (1996). GPOWER: A general power analysis program. Behavior Research Methods, Instruments \& Computers, 28(1), 1-11.

Erikson, E. H. (1968). Identity: youth and crisis. Oxford England: Norton \& Co.

Fivush, R., Marin, K., McWilliams, K., \& Bohanek, J. G. (2009). Family reminiscing style: Parent gender and emotional focus in relation to child well-being. Journal of Cognition and Development, 10(3), 210-235. doi:10.1080/15248370903155866

Fivush, R., \& Nelson, K. (2006). Parent-child reminiscing locates the self in the past. British Journal of Developmental Psychology, 24(1), 235-251. doi:10.1348/026151005x57747

Fraley, R. C., \& Davis, K. E. (1997). Attachment formation and transfer in young adults' close friendships and romantic relationships. Personal Relationships, 4, 131-144.

Habermas, T., \& Bluck, S. (2000). Getting a life: The development of the life story in adolescence. Psychological Bulletin, 126, 748-769. 
Habermas, T., Negele, A., \& Mayer, F. B. (2010). "Honey, you're jumping about”-Mothers' scaffolding of their children's and adolescents' life narration. Cognitive Development, 25(4), 339-351. doi:10.1016/j.cogdev.2010.08.004

Hartup, W. W., \& Stevens, N. (1997). Friendships and adaptation in the life course. Psychological Bulletin, 121, 355-370.

Jennings, L., McLean, K. C., \& Pasupathi, M. (2013). Intricate lettings out and lettings in: Listener Scaffolding of Narrative Identity in Newly-Dating Romantic Partners. Self and Identity, 13, 214-230.

Kalmijn, M., \& De Graaf, P. M. (2012). Life course changes of children and well-being of parents. Journal of Marriage and Family, 74(2), 269-280. doi:10.1111/j.17413737.2012.00961.x

Keijsers, L., Branje, S., Frijns, T., Finkenauer, C., \& Meeus, W. (2010). Gender Differences in Keeping Secrets From Parents in Adolescence. Developmental Psychology, 46. 293-8. $10.1037 / \mathrm{a} 0018115$.

Kerr, M., \& Stattin, H. (2000). What parents know, how they know it, and several forms of adolescent adjustment: Further support for a reinterpretation of monitoring. Developmental Psychology, 36(3), 366-380. doi:10.1037/0012-1649.36.3.366

Köber, C., Schmiedek, F., \& Habermas, T. (2015). Characterizing lifespan development of three aspects of coherence in life narratives: A cohort-sequential study. Developmental Psychology, 51(2), 260-275. doi:10.1037/a0038668

Liao, H.-W., Bluck, S., Alea, N., \& Cheng, C.-L. (2016). Functions of autobiographical memory in Taiwanese and American emerging adults. Memory, 24(4), 423-436. doi:10.1080/09658211.2015.1015572 
Lilgendahl, J. P., \& McAdams, D. P. (2011). Constructing stories of self-growth: How individual differences in patterns of autobiographical reasoning relate to well-being in midlife. Journal of Personality, 79(2), 391-428. doi:10.1111/j.1467-6494.2010.00688.x

Lilgendahl, J. P., \& McLean, K. C. (2019). Narrative Identity Processes and Changes in Wellbeing Across the Transition to College: A Contextualized Approach. Manuscript Under Review.

Lilgendahl, J. P., McLean, K. C., \& Mansfield, C. D. (2013). When is meaning making unhealthy for the self? The roles of neuroticism, implicit theories, and memory telling in trauma and transgression memories. Memory, 21(1), 79-96.

doi:10.1080/09658211.2012.706615

Mansfield, C. D., McLean, K. C., \& Lilgendahl, J. P. (2010). Narrating traumas and transgressions: Links between narrative processing, wisdom, and well-being. Narrative Inquiry, 20(2), 246-273. doi:10.1075/ni.20.2.02man

Mansfield, C. D., Pasupathi, M., \& McLean, K. C. (2015). Is narrating growth in stories of personal transgressions associated with increased well-being, self-compassion, and forgiveness of others? Journal of Research in Personality, 58, 69-83.

McAdams, D. P. (1993). The stories we live by: Personal myths and the making of the self. New York: Guilford Press.

McAdams, D. P. (1996). Personality, modernity, and the storied self: A contemporary framework for studying persons. Psychological Inquiry, 7, 295-321.

McAdams, D. P., Hoffman, B. J., Mansfield, E. D., \& Day, R. (1996). Themes of agency and communion in significant autobiographical scenes. Journal of Personality, 64, 339-377. 
McAdams, D. P., \& McLean, K. C. (2013). Narrative identity. Current Directions in Psychological Science, 22(3), 233-238. doi:10.1177/0963721413475622

McGregor, I., \& Holmes, J. G. (1999). How storytelling shapes memory and impressions of relationship events over time. Journal of Personality and Social Psychology, 76, 403419.

McLean, K. C. (2005). Late adolescent identity development: Narrative meaning-making and memory telling. Developmental Psychology, 41, 683-691.

McLean, K. C. (2015). The co-authored self: Family stories and the construction of personal identity. New York, NY, US: Oxford University Press.

McLean, K. C., Breen, A. V., \& Fournier, M. A. (2010). Constructing the self in early, middle, and late adolescent boys: Narrative identity, individuation, and well-being. Journal of Research on Adolescence, 20(1), 166-187.

McLean, K. C., \& Jennings, L. E. (2012). Teens telling tales: How maternal and peer audiences support narrative identity development. Journal of Adolescence, 35(6), 1455-1469.

McLean, K. C., \& Lilgendahl, J. P. (2008). Why recall our highs and lows: Relations between memory functions, age, and well-being. Memory, 16(7), 751-762. doi:10.1080/09658210802215385

McLean, K. C., \& Mansfield, C. D. (2012). The co-construction of adolescent narrative identity: Narrative processing as a function of adolescent age, gender, and maternal scaffolding. Developmental Psychology, 48(2), 436-447. doi:10.1037/a0025563

McLean, K. C., \& Pasupathi, M. (2011). Old, new, borrowed, Blue? The emergence and retention of personal meaning in autobiographical storytelling. Journal of Personality, 79(1), 135-164. doi:10.1111/j.1467-6494.2010.00676.x 
McLean, K. C., Pasupathi, M., Fivush, R., \& Greenhoot, A. F. (under review). Does within person variability in narration matter and for what? Journal of Research in Personality.

McLean, K. C., \& Pratt, M. W. (2006). Life's Little (and Big) Lessons: Identity Statuses and Meaning-Making in the Turning Point Narratives of Emerging Adults. Developmental Psychology, 42(4), 714-722.

McLean, K. C., \& Syed, M. (2015). Personal, master, and alternative narratives: An integrative framework for understanding identity development in context. Human Development, 58(6), 318-349. doi:10.1159/000445817

Nils, F., \& Rimé, B. (2012). Beyond the myth of venting: Social sharing modes determine the benefits of emotional disclosure. European Journal of Social Psychology, 42(6), 672-681. doi:10.1002/ejsp. 1880

Pals, J. L. (2006). Narrative identity processing of difficult life experiences: Pathways of personality development and positive self-transformation in adulthood. Journal of Personality, 74, 1079-1110.

Pasupathi, M. (2007). Telling and the remembered self: Linguistic differences in memories for previously disclosed and previously undisclosed events. Memory, 15(3), 258-270.

Pasupathi, M., Billitteri, J., Mansfield, C. D., Wainryb, C., Hanley, G., \& Taheri, K. (2015). Regulating emotion and identity by narrating harm. Journal of Research in Personality, $58,127-136$.

Pasupathi, M., Carstensen, L. L., Levenson, R. W., \& Gottman, J. M. (1999). Responsive listening in long-married couples: A psycholinguistic perspective. Journal of Non-Verbal Behavior, 23, 173-193. 
Pasupathi, M., \& Hoyt, T. (2009). The development of narrative identity in late adolescence and emergent adulthood: The continued importance of listeners. Developmental Psychology, 45(558-574).

Pasupathi, M., \& Hoyt, T. (2010). Silence and the shaping of memory: How distracted listeners affect speakers' subsequent recall of a computer game experience. Memory, 18(2), 159169. doi:10.1080/09658210902992917

Pasupathi, M., Mansour, E., \& Brubaker, J. R. (2007). Developing a life story: Constructing relations between self and experience in autobiographical narratives. Human Development, 50(2), 85-110.

Pasupathi, M., McLean, K. C., \& Weeks, T. (2009). To tell or not to tell: Disclosure and the narrative self. Journal of Personality, 77, 1-35.

Pasupathi, M., \& Oldroyd, K. (2015). Telling and remembering: Complexities in long-term effects of listeners on autobiographical memory. Applied Cognitive Psychology. doi:10.1002/acp.3193

Pasupathi, M., \& Wainryb, C. (2010). On telling the whole story: Facts and interpretations in memory narratives from childhood through adolescence. Developmental Psychology, 46, 735-746.

Pasupathi, M., \& Wainryb, C. (2018). Remembering good and bad times together: Functions of collaborative remembering. In M. L. Meade, C. Harris, P. Van Bergen, J. Sutton, \& A. J. Barnier (Eds.), Collaborative remembering: Theories, research, and applications. (pp. 261-279). Oxford, England: Oxford University Press.

Recchia, H. E., \& Wainryb, C. (2014). Mother-child conversations about hurting others: Supporting the construction of moral agency through childhood and adolescence. In C. 
Wainryb \& H. E. Recchia (Eds.), Talking about Right and Wrong: Parent-child conversations as contexts for moral development (pp. 242-269). New York City, NY USA: Cambridge University Press.

Recchia, H. E., Wainryb, C., Bourne, S., \& Pasupathi, M. (2014). The Construction of Moral Agency in Mother-Child Conversations about Helping and Hurting Across Childhood and Adolescence. Developmental Psychology, 50, 34-44.

Reese, E., \& Brown, N. (2000). Reminiscing and recounting in the preschool years. Applied Cognitive Psychology, 14, 1-17.

Reese, E., Chen, Y., McAnally, H. M., Myftari, E., Neha, T., Wang, Q., \& Jack, F. (2014). Narratives and traits in personality development among New Zealand Māori, Chinese, and European adolescents. Journal of Adolescence, 37(5), 727-737. doi:10.1016/j.adolescence.2014.02.005

Reese, E., Haden, C. A., \& Fivush, R. (1993). Mother-child conversations about the past: Relationships of style and memory over time. Cognitive Development, 8(4), 403-430.

Reese, E., Jack, F., \& White, N. (2010). Origins of adolescents' autobiographical memories. Cognitive Development, 25(4), 352-367. doi:10.1016/j.cogdev.2010.08.006

Reese, E., Yan, C., Jack, F., \& Hayne, H. (2010). Emerging identities: Narrative and self from early childhood to early adolescence. In K. C. McLean \& M. Pasupathi (Eds.), Narrative development in adolescence: Creating the storied self. (pp. 23-43). New York, NY US: Springer Science + Business Media.

Ryff, C. D., Lee, Y. H., Essex, M. J., \& Schmutte, P. S. (1994). My children and me: Midlife evaluations of grown children and of self. Psychology and Aging, 9(2), 195-205. doi:10.1037/0882-7974.9.2.195 
Shaver, P., Furman, W., \& Buhrmeister, D. (1985). Transition to college: Network changes, social skills, and loneliness. In S. Duck \& D. Perlman (Eds.), Understanding personal relationships: An interdisciplinary approach (pp. 193-219). London: Sage

Syed, M., \& McLean, K. C. (2016). Understanding identity integration: Theoretical, methodological, and applied issues. Journal of Adolescence, 47, 109-118. doi:10.1016/j.adolescence.2015.09.005

Syed, M., \& Nelson, S. C. (2015). Guidelines for establishing reliability when coding narrative data. Emerging Adulthood, 3(6), 375-387. doi:10.1177/2167696815587648

Tversky, B., \& Marsh, E. J. (2000). Biased retellings of events yield biased memories. Cognitive Psychology, 40(1), 1-38.

Weeks, T. L., \& Pasupathi, M. (2010). Autonomy, identity, and narrative construction with parents and friends. In K. C. McLean \& M. Pasupathi (Eds.), Narrative development in adolescence: Creating the storied self. (pp. 65-91). New York, NY US: Springer Science + Business Media.

Weeks, T. L., \& Pasupathi, M. (2011). Stability and change self-integration for negative events: The role of listener responsiveness and elaboration. Journal of Personality, 79(3), 469498. doi:10.1111/j.1467-6494.2011.00685.x 


\section{Author Note}

The authors would like to thank Bree Hibbert, Lyndsay Tolbert, Lindsey Heward, Allison Forrest Riana Culp, Reagan Groscost Favreau, Lindsey Barnes Heward, Bree Hibbert, Lyndsi Tolbert Holbrook, Rachel Kellett, Grayson Hull, Shannon Nielsen, and Mary Schmuhl and Ms. Martin for their work in coding the narratives for Study 2 along elaboration, exploration, growth, damage, and resolution. Jasmine Robinson is appreciated for her work on coding the edits in Study 2 . 
Table 1: Descriptive data for Survey Findings

\begin{tabular}{lllll}
\hline & Fathers & Mothers & Friends & $\begin{array}{l}\text { Romantic } \\
\text { Partners }\end{array}$ \\
\hline Sample 1 & & & & \\
Frequency & $3.7(1.7)$ & $4.5(1.5)$ & $5.4(1.4)$ & $\mathrm{n} / \mathrm{a}$ \\
Self-related Purposes & $4.1(1.4)$ & $4.4(1.3)$ & $5.1(1.2)$ & $\mathrm{n} / \mathrm{a}$ \\
Social Purposes & $3.8(1.4)$ & $4.3(1.2)$ & $5.4(1.0)$ & $\mathrm{n} / \mathrm{a}$ \\
Comfort & $4.2(1.8)$ & $5.0(1.8)$ & $5.8(1.3)$ & $\mathrm{n} / \mathrm{a}$ \\
Supportive Listening & $4.9(1.0)$ & $5.2(1.0)$ & $5.3(0.8)$ & $\mathrm{n} / \mathrm{a}$ \\
Challenging/Hostile & $2.9(1.2)$ & $2.9(1.2)$ & $2.4(1.0)$ & $\mathrm{n} / \mathrm{a}$ \\
Listening & & & & \\
& & & & \\
Sample 2 & & & & \\
Frequency & $3.2(1.7)$ & $4.6(1.9)$ & $5.2(1.4)$ & $5.4(1.6)$ \\
Self-related Purposes & $3.8(1.6)$ & $4.6(1.6)$ & $5.1(1.2)$ & $5.1(1.4)$ \\
Social Purposes & $3.4(1.5)$ & $4.4(1.6)$ & $5.3(1.1)$ & $5.5(1.4)$ \\
Comfort & $3.9(1.9)$ & $4.9(1.9)$ & $5.8(1.3)$ & $5.8(1.4)$ \\
\hline
\end{tabular}


Table 2: Estimated Marginal Means (Standard Error of Mean) of Narrative Qualities by Event Type and Audience

\begin{tabular}{|c|c|c|c|c|c|c|c|c|c|c|c|c|}
\hline & \multicolumn{3}{|c|}{ Low Point } & \multicolumn{3}{|c|}{ Transgression } & \multicolumn{3}{|c|}{ Turning Point } & \multicolumn{3}{|c|}{ High Point } \\
\hline $\begin{array}{l}\text { Elaborat } \\
\text { ion }\end{array}$ & \multicolumn{3}{|c|}{$2.44(.05)$} & \multicolumn{3}{|c|}{$2.16(.06)$} & \multicolumn{3}{|c|}{$2.19(.05)$} & \multicolumn{3}{|c|}{$2.22(.05)$} \\
\hline $\begin{array}{l}\text { Explorat } \\
\text { ion }\end{array}$ & \multicolumn{3}{|c|}{$1.88(.06)$} & \multicolumn{3}{|c|}{$1.69(.06)$} & \multicolumn{3}{|c|}{$1.92(.06)$} & \multicolumn{3}{|c|}{$1.54(.06)$} \\
\hline Growth & \multicolumn{3}{|c|}{$1.30(.08)$} & \multicolumn{3}{|c|}{$1.09(.08)$} & \multicolumn{3}{|c|}{$1.98(.06)$} & \multicolumn{3}{|c|}{$1.56(.07)$} \\
\hline Damage & \multicolumn{3}{|c|}{$.69(.06)$} & \multicolumn{3}{|c|}{$.55(.05)$} & \multicolumn{3}{|c|}{$.08(.02$} & \multicolumn{3}{|c|}{$.01(.01)$} \\
\hline Resoluti & \multicolumn{3}{|c|}{$.27(.07)$} & \multicolumn{3}{|c|}{$.20(.06)$} & \multicolumn{3}{|c|}{$.31(.04)$} & \multicolumn{3}{|c|}{$.12(.02)$} \\
\hline & \multicolumn{3}{|c|}{$\begin{array}{l}\text { Original } \\
\text { Instructions }\end{array}$} & \multicolumn{3}{|c|}{ Mothers } & \multicolumn{3}{|c|}{ Friends } & & & \\
\hline $\begin{array}{l}\text { Elaborat } \\
\text { ion }\end{array}$ & \multicolumn{3}{|c|}{$2.3(.04$} & $2.2(.05$ & & & 2.3 & 05) & & & & \\
\hline $\begin{array}{l}\text { Explorat } \\
\text { ion }\end{array}$ & 1.7( & 66) & & $1.9(.0$ & & & 1.7 & $.05)$ & & & & \\
\hline Growth & 1.5( & 6) & & $1.7(.06$ & & & 1.3 & 06) & & & & \\
\hline Damage & 0.4 & 03) & & $0.2(.0$ & & & 0.3 & $.03)$ & & & & \\
\hline Resoluti & 0.2 & 03) & & $0.3(.0$ & & & 0.2 & $.04)$ & & & & \\
\hline & Lov & Point & & Transg & ession & & Tur & ing Poi & & Hig & Point & \\
\hline & $\mathrm{O}$ & M & $\mathrm{F}$ & $\mathrm{O}$ & M & $\mathrm{F}$ & $\mathrm{O}$ & $\mathrm{M}$ & $\mathrm{F}$ & & M & $\mathrm{F}$ \\
\hline Elaborat & 2.5 & 2.4 & 2.5 & 2.2 & 2.1 & 2.2 & 2.2 & 2.1 & 2.2 & 2.2 & 2.2 & 2.3 \\
\hline & $(.0$ & $(.0$ & $(.0$ & $(.06)$ & $(.07)$ & $(.07)$ & $(.0$ & $(.06)$ & $(.07)$ & $(.0$ & $(.06)$ & $(.06)$ \\
\hline & 5) & 7) & 6) & & & & $6)$ & & & 5) & & \\
\hline Explorat & 1.7 & 2.0 & 1.9 & $1.7(.0$ & $1.8(.0$ & 1.6 & 1.8 & 2.0 & 1.9 & 1.4 & $1.7(.7$ & $1.5(.0$ \\
\hline ion & $(.0$ & $(.0$ & $(.0$ & 8) & 7) & $(.06)$ & $(.0$ & $(.06)$ & $(.07)$ & $(.0$ & $0)$ & 6) \\
\hline & 8) & 8) & 7) & & & & 7) & & & 8) & & \\
\hline Growth & 1.3 & 1.4 & 1.2 & $1.0(.0$ & $1.2(.0$ & $1.0(.0$ & 2.0 & $2.1(.0$ & $1.9(.0$ & 1.6 & 1.8 & 1.3 \\
\hline & $(.0$ & $(.0$ & $(.0$ & 9) & 9) & 9) & $(.0$ & 7) & 8) & $(.0$ & $(.07)$ & $(.09)$ \\
\hline & 9) & 9) & 9 & & & & 8) & & & 9) & & \\
\hline Damage & 0.7 & 0.6 & 0.8 & 0.8 & 0.3 & 0.5 & 0.1 & 0.1 & 0.1 & 0.0 & 0.0 & 0.0 \\
\hline & $(.0$ & $(.0$ & $(.0$ & $(.07)$ & $(.05)$ & $(.06)$ & $(.0$ & $(.03)$ & $(.02)$ & $(.0$ & $(.01)$ & $(.01)$ \\
\hline & 6) & 7) & 8) & & & & 3) & & & 1) & & \\
\hline Resoluti & .32 & .40 & .09 & .29 & .21 & .10 & .19 & .35 & .39 & .10 & .10 & .16 \\
\hline on & $(.0$ & $(.0$ & $(.0$ & $(.09)$ & $(.07)$ & $(.07)$ & $(.0$ & $(.05)$ & $(.06)$ & $(.0$ & $(.02)$ & $(.03)$ \\
\hline & 8) & 7) & 8) & & & & 5) & & & 3) & & \\
\hline
\end{tabular}

